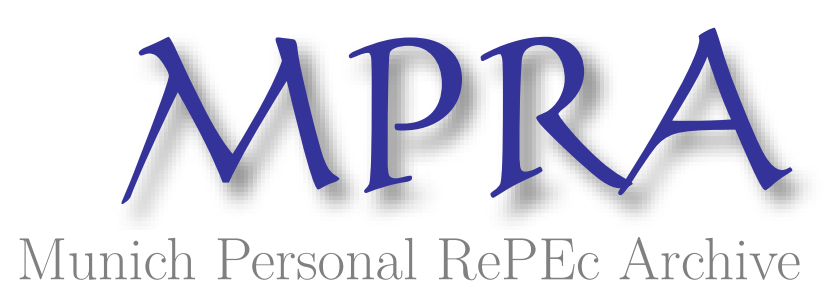

\title{
Assessing the readiness of BRICS grouping for mutually beneficial financial integration
}

Bonga-Bonga, Lumengo

University of Johannesburg

10 December 2014

Online at https://mpra.ub.uni-muenchen.de/60701/

MPRA Paper No. 60701, posted 17 Dec 2014 14:00 UTC 
Author: $\quad$ Professor Lumengo Bonga-Bonga

Affiliation: University of Johannesburg

Paper Title: Assessing the readiness of BRICS grouping for mutually beneficial financial integration

This paper assesses the extent of the transmission of equity market volatility shocks between BRICS (Brazil, Russia, India, China and South Africa) countries to infer the degree of risk sharing and the possibility of a beneficial financial integration between its member countries. The paper makes use of the spillover index methodology suggested by Diebold and Yilmaz (2012) to this end. Nonetheless, the paper extends this methodology by making use of ex ante volatility measures that account for long memory in equity markets. The paper finds asymmetric influences between BRICS countries in relation to the cross transmission of risks. The finding of the paper implies the possibility of unequal benefit that could result from a possible capital market liberalisation between the BRICS countries.

\section{JEL classification: G15, C10}

Email: lbonga@uj.ac.za 
Introduction

At the time when a number of agreements and treaties aiming at strengthening financial and economic cooperation between BRICS countries are being concluded, it is evident that the ultimate aim of the BRICS grouping is to further its financial and economic integration with the possibility of scrapping any barrier to capital movement such as the component countries' respective exchange control regulations. Nonetheless, such a decision for capital market liberalisation among BRICS member countries should be informed by economic factors rather than simply by political stance if capital market liberalisation is deemed to be mutually beneficial among all the member countries.

It is unfortunate that the approach to financial integration or capital market liberalisation has often been driven as much by philosophy and political circumstances as by economic factors (Kose, et al., 2009). The benefit of capital market liberalisation may be unequally shared when such a decision is taken without consideration of economic and financial dynamics.

Risk sharing in the context of cross transmission of volatility has been evoked as the most important prerequisite for beneficial financial integration or capital market liberalisation. (Kose et al., 2009)). Moreover, Bekaert et al. (2005) show that the positive link between capital market liberalisation and economic growth is made possible through the lower cost of capital that is derived through risk sharing. Risk sharing between countries encourages cross holding of foreign assets, which insures domestic residents against country-specific shocks to their income. Risk sharing logically allows for greater diversification of income risk, which, in turn, spurs economic growth through greater specialisation (Kose et al., 2011; Kalemli-Ozcan, 2003). This reality suggests that the increased probability of cross transmission of shocks between country members of a specific grouping not only indicates the increased degree of financial integration but also shows the possibility of a beneficial cooperation. Thus, successful and beneficial capital market liberalization between BRICS countries should be conditioned upon the existence of risk sharing or cross transmission of their market volatility or risk.

Against this background, this paper endeavours to assess the extent and magnitude of cross transmission of equity-market volatility shocks among the BRICS to infer the economic benefit that could result from possible capital market liberalization. The results of this paper should inform policy makers of BRICS member countries whether it would be beneficial at this juncture of time to further liberalise their capital market by scrapping the existing exchange control regulation for a free flow of capital within the grouping.

Given that exchange control regulation is applied in order to insulate countries against massive capital outflow and possible currency crisis, especially during major global and internal financial crisis, it is important to ascertain that any reversal of the regulation - albeit only among BRICS partners - will not affect small countries such as South Africa. The premise of this paper is that BRICS countries, especially small countries within BRICS such as South Africa, need to ascertain that the precondition for risk sharing or cross transmission of volatility shocks is fulfilled before attempting to further liberalise their capital markets. 
It is well documented that in the context of globalization, big economies are the beneficiaries of capital flow, to the detriment of small economies, especially during periods of financial crises. For example, Mendoza et al. (2009) show that the United States (US) has increased its net holding of risky assets, characterized by equity portfolio and FDI, since the inception of globalization in the 1980s. This situation arises mainly because investors perceive the US as a safe haven for their assets and that there is massive capital flow from risky economies to safer economies such as the US during major financial crises. Moreover, Stiglitz (2002), referring to the darker side of globalization, indicates that much of the instability that occurred in East Asia in the mid-1990s was because the affected countries yielded to the pressure for capital market liberalization without properly shielding their economies. The author supports safeguard measures such as exchange control regulation to manage the risk of capital market liberalization characterised by massive capital flow from less-developed economies to industrial economies.

It is intuitive that the US will attract capital flow from less developed countries, especially during the crisis periods, simply because there is no reciprocity or cross transmission of risks or volatilities between the US and less developed economies. Crisis in the US can contaminate lessdeveloped economies and the contrary is probably not evident. In the absence of risk sharing or cross transmission of shocks among countries, the benefits of financial liberalisation are unequally shared among nations. Countries that are able to transmit risks to others without being themselves exposed by risks from those countries are set to become the main beneficiary and recipients of portfolio and direct investment inflow at the cost of countries that are fragile and susceptible to contaminations from external risks.

The difference in the size of BRICS economies may raise a concern on their mutual influence in terms of cross transmission of volatility shocks. China is the biggest economy of the BRICS countries. China's GDP in 2011 was by far the largest among the BRICS economies (World Bank, 2012). South Africa is the smallest economy in the BRICS grouping with a population of 50 million, close to 27 times less than in China. The 2011 GPD of South Africa was close to 18 times less than that of China, 6 times less than Brazil and 4 times less than Russia and India (World Bank, 2012). Moreover, the market capitalisation of the biggest mainland China's stock exchange, Shanghai Stock Exchange, is 5 times the market capitalisation of the South African's stock exchange, the Johannesburg stock exchange in 2011 (IMF, 2012). This notable difference in the size of the two economies may indicate the possibility of an unequal benefit that may arise from further financial liberalisation in the absence of risk sharing.

In order to assess the extent and magnitude of risk sharing or cross transmission of volatility shocks between BRICS countries, this paper makes use of the spillover measure based on forecast error variance decompositions from vector autoregressions (VARs) as proposed by Diebold and Yilmaz (2009, 2012). The paper extends this methodology by modelling ex ante volatility spillover of the BRICS countries, whereby volatility series of BRICS countries are computed on the basis of a fractionally integrated general autoregressive conditional heteroskedastic (FIGARCH) model to account for long memory in their respective equity markets. 
The empirical results of the cross transmission of volatility shocks show that risks are shared asymmetrically between BRICS countries and that South Africa, a smaller BRICS country, is more of a receiver than a transmitter of volatility shocks in the grouping.

The paper proceeds as follows. In Section 2, the methodological approach is discussed with a particular focus on the FIGARCH model, as well as on volatility spillover approach used in the paper. Section 3 presents the results of the paper and the conclusion of the paper is provided in Section 4.

\section{Methodology}

In order to assess the cross transmission of volatility shocks between BRICS economies, this paper employs the spillover index framework suggested by Diebold and Yilmaz $(2009,2012)$ and extends the framework to the case of ex ante volatility spillover with volatility series obtained from FIGARCH model.

Diebold and Yilmaz's spillover index is based on the vector autoregressive model (VAR) model specified as:

$$
Y_{t}=\beta Y_{t-1}+\varepsilon_{t}
$$

Where $Y_{t}$ is the vector of equity return volatilities of BRICS countries as in this paper. Applying Wold decomposition in Equation 1, the following moving average of the VAR is obtained as:

$$
Y_{t}=\Theta(L) \varepsilon_{t}
$$

where $\Theta(L)=(1-\beta L)^{-1}$. The structural form of Equation 2 can be represented as $Y_{t}=A(L) \mu_{t}$

where $A(L)=\Theta(L) Q_{t}^{-1}$ and $\mu_{t}=Q_{t} \varepsilon_{t} . Q_{t}$ can be identified by using the lower-triangular Choleski decomposition or any other identification scheme, depending on a chosen goal.

With a 1-step-ahead forecasting given by

$$
Y_{t+1}=\beta Y_{t}
$$

and the error vector of the $n$ variables in the vector $Y_{t}$ represented by

$$
e_{t+1, t}=Y_{t+1}-Y_{t+1, t}=A_{0} \mu_{t+1}=\left[\begin{array}{llll}
a_{0,11} & a_{0,12} & \ldots & a_{0,1 n} \\
a_{0,21} & a_{0,22} & \ldots & a_{0,2 n} \\
\cdot & & & \\
\cdot & & & \\
\cdot & & & \\
a_{0, n 1} & a_{0, n 2} & \ldots & a_{0, n n}
\end{array}\right]\left[\begin{array}{l}
\mu_{1, t+1} \\
\mu_{2, t+1} \\
\cdot \\
\cdot \\
\cdot \\
\mu_{n, t+1}
\end{array}\right]
$$

and its covariance can be expressed as 
With this notation, the variance of the one-step error in forecasting $Y_{1 t}$ is expressed as:

$a_{0,11}^{2}+a_{0,12}^{2}+\ldots+a_{0,1 n}^{2}$.

Diebold and Yilmaz made a difference between 'own variance shares' and 'cross variance shares' where the former refers to the fraction of the one-step-ahead error variances in forecasting $y_{i}$ due to shocks to $y_{i}$ and the latter, also known as 'spillover', refers to the fractions of the 1-stepahead error variances in forecasting $y_{i}$ due to shocks to $y_{j}$ with $i \neq j$. Total spillover can be obtained by summing up all the cross variance shares. Therefore, the spillover index is obtained by the ratio of the total spillover and the total forecast error variation, also known as $\operatorname{trace}\left(A_{0} A_{0}\right)$. This spillover index is obtained by assuming orthogonalisation based on Cholesky decomposition or factorisation, which is order dependent in a VAR framework. To obtain a spillover index that is independent of the results of ordering, Diebold and Yilmaz (2012) show that the generalised VAR framework of Pesaran and Shin (1998) can be applied. Thus the volatility spillover index can be obtained as

$$
S^{g}(H)=\frac{\sum_{i, j=1}^{N}, i \neq j}{\left.\theta_{i j}^{g} \tilde{(} H\right)} .100
$$

Where $\tilde{\theta}_{i j}^{g}(H)$ is the normalised H-step-ahead generalised forecast error variance decomposition, which is independent of the order of variables in the VAR system (see Koop, et. al.,, 1996; Pesaran and Shin, 1998). $S^{g}(H)$ is the spillover index.

Contrary to the study by Diebold and Yilmaz $(2009,2012)$ that made use of the realised volatility to obtain the time series of market volatility, this paper constructs the elements of vector $Y_{t}$, the volatility series, with the aid of the FIGARCH model to account for a long memory of equity market volatility and the persistence of its shocks. It is important to note that in the tradition of volatility modelling, the IGARCH model has been often used to account for long memory of volatility series and the persistence of its shocks (Lamoureux and Lastrapes, 1990). Nonetheless, Baillie et al. (1996) contend that the IGARCH model is too restrictive, as it implies an infinite persistence of volatility shocks. The authors introduce the FIGARCH model, which accounts for the presence of long memory. However, the model allows a slow hyperbolic rate of decay of volatility shocks.

It can be proven that the IGARCH model is a particular case of the FIGARCH model. Given for example an IGARCH (p,q) expressed as 
$h_{t}=\alpha_{0}+\sum_{i=1}^{q} \alpha_{i} \varepsilon_{t-i}^{2}+\sum_{j=1}^{p} \beta_{j} h_{t-j}$

with $\sum_{i=1}^{q} \alpha_{i}+\sum_{j=1}^{p} \beta_{j}=1$

Equation 6 can be written as

$h_{t}=\alpha_{0}+\alpha(L) \varepsilon_{t}^{2}+\beta(L) h_{t}$

Where $\mathrm{L}$ is the lag operator and $\alpha(L)=\alpha_{1} L+\alpha_{2} L+\ldots+\alpha_{q} L . h_{t}$ is the conditional variance.

The IGARCH model can be expressed as an ARMA process in $\varepsilon_{t}^{2}$ as follows:

$[1-\alpha(L)-\beta(L)](1-L) \varepsilon_{t}^{2}=\alpha 0+[1-\beta(L)] v_{t}$

Where $v_{t}=\varepsilon_{t}^{2}-h_{t}$ and it is interpreted as the shock to conditional variance.

Baillie et al. (1996) show that the FIGARCH model is obtained by replacing the first difference operator $(1-L)$ in the above equation by $(1-L)^{d}$ with $0<d<1$. Thus, the ARMA representation of the FIGARCH model is written as

$[1-\alpha(L)-\beta(L)](1-L)^{d} \varepsilon_{t}^{2}=\alpha_{0}+[1-\beta(L)] v_{t}$

The alternative representation of Equation 9 is obtained as

$[1-\beta(L)] h_{t}=\alpha_{0}+\left[1-\beta(L)-\phi(L)(1-L)^{d}\right] \varepsilon_{t}^{2}$

It is clear from this representation that if $d$ is close to unity, the FIGARCH model becomes closer to an IGARCH model, indicating long persistence of volatility shocks.

\section{Data, Empirical analysis and Discussion of Results}

The ex ante volatility series used to estimate the volatility spillover index between BRICS countries are modelled with the use of the FIGARCH model. The volatility series is obtained in two steps. First, BRICS equity market returns are computed as the first difference of the natural logarithm of equity market indices. Data are weekly local-currency equity market indices made of MICEX index (Russia), Johannesburg All Share Index (South Africa), S\&P CNX Nifty index (India), BOVESPA index (Brazil) and the Shanghai stock exchange index, A share and B share (China). The sample period spans from January 1998 to December 2011. The FIGARCH $(1, \mathrm{~d}, 1)$ model is used to estimate the conditional volatility series for each of the countries that are used to compute spillover index. The order of the model is determined according to the Akaike Information Criteria (AIC).

Figure A1, in the appendix, displays the autocorrelation function of the absolute returns of each country. It is clear from the figure that there is hyperbolic decay of the autocorrelation function 
for most absolute return series. This occurrence indicates the possibility of modelling volatility with a long memory model, such as the FIGARCH model.

The following FIGARCH $(1, \mathrm{~d}, 1)$ model is fitted by the quasi maximum likelihood estimator (QMLE) for all the countries:

$$
\begin{aligned}
& y_{t}=c+\varepsilon_{t}, \\
& \varepsilon_{t}=Z_{t} h_{t}^{1 / 2} \text { and } Z_{t} \sim \text { i.i.d.N }(0,1) \\
& h_{t}=\alpha_{0}+\beta_{1} h_{t}-1+\left[1-\beta_{1} L-\left(1-\phi_{1} L\right)(1-L)^{d}\right] \varepsilon_{t}^{2}
\end{aligned}
$$

Where $c$ is a constant mean.

The results of the estimation of Equations 12 and 13 are reported in Table 1.

Table 1 Estimated FIGARCH $(1, \mathrm{~d}, 1)$ model

\begin{tabular}{|l|l|l|l|l|l|}
\hline & Russia & South Africa & India & Brazil & China \\
\hline Coefficients & & & & & \\
\hline$c$ & $0.579^{*}$ & $0.351^{* *}$ & $0.492^{*}$ & $0.391^{*}$ & 0.089 \\
\hline$\alpha_{0}$ & 3.655 & $2.425^{* * *}$ & $2.467^{* *}$ & $9.212^{* *}$ & 1.007 \\
\hline$\beta_{1}$ & $-0.961^{*}$ & 0.018 & $-0.436^{*}$ & $-0.758^{*}$ & 0.309 \\
\hline$\phi_{1}$ & $-0.950^{*}$ & -0.176 & $-0.578^{*}$ & $-0.743^{*}$ & 0.132 \\
\hline$d$ & $0.255^{*}$ & $0.289^{*}$ & $0.350^{*}$ & $0.22^{*}$ & $0.355^{* *}$ \\
\hline$Q(50)$ & $8.25(0.89)$ & $60.90(0.13)$ & $63.73(0.091)$ & $52.27(0.385)$ & $78.28(0.006)$ \\
\hline$Q^{2}(50)$ & $59.28(0.124)$ & $49.45(0.413)$ & $44.45(0.619)$ & $27.47(0.992)$ & $41.82(0.722)$ \\
\hline Loglikelihood & -2172.37 & -1898.438 & -1881.65 & -2091.941 & -1767 \\
\hline
\end{tabular}

$*$, ** and $* * *$ denote $1 \%, 5 \%$ and $10 \%$ level of significance, respectively. Expression in bracket indicates probability for the rejection of the null hypothesis.

The results reported in Table 1 show that the coefficients of the FIGARCH $(1,1)$ are statistically significant and the positivity constraint for the model is observed, especially for Russia, India and Brazil. Moreover the misspecification tests, in particular the Ljung-Box portmanteau test of up to 50 lags (Q50) for no serial correlation in the standardised and the squared standardised residuals, show that the null hypotheses of no serial correlation are not rejected at the $5 \%$ level - at least for all countries except China. Moreover, a number of coefficients of the FIGARCH model for South Africa are statistically not significant. It is clear from the estimation that the conditional volatility of equity markets for South Africa and China could not be fitted with a FIGARCH model. Thus, based on the likelihood statistics, the conditional volatility of China's equity market was fit with a the Exponential GARCH (EGARCH $(1,1))$ model. The loglikelihood for this model is estimated at -1766.30 compared with -1767.813 for the FIGARCH $(1,1)$ model of the same country. The figures confirm the best fit of EGARCH model China. Nonetheless, the conditional volatility of the South African equity market formed a better fit with a GARCH $(1,1)$ model, improving the loglikelihood to -1897.61 , compared to -1898.438 for the case of the FIGARCH(1,1) model. 
Figure 1 displays the ex ante or conditional volatility series of the BRICS countries obtained from the different GARCH models, as discussed above. These volatility series are used to compute the spillover index between BRICS countries as per the objective of this paper. Nonetheless, it is worth noting from Figure 1 that conditional volatility in BRICS countries reacts in tandem mostly to global volatility shocks, such as the 2007-2008 global financial crisis. Moreover, Figure 1 shows that there is some evidence of the reaction of the BRICS' equity market conditional volatilities to regional shocks, such as the Russian currency crisis in 1998 and the South American economic crisis of 2002.

Figure 1 Volatility series of BRICS countries
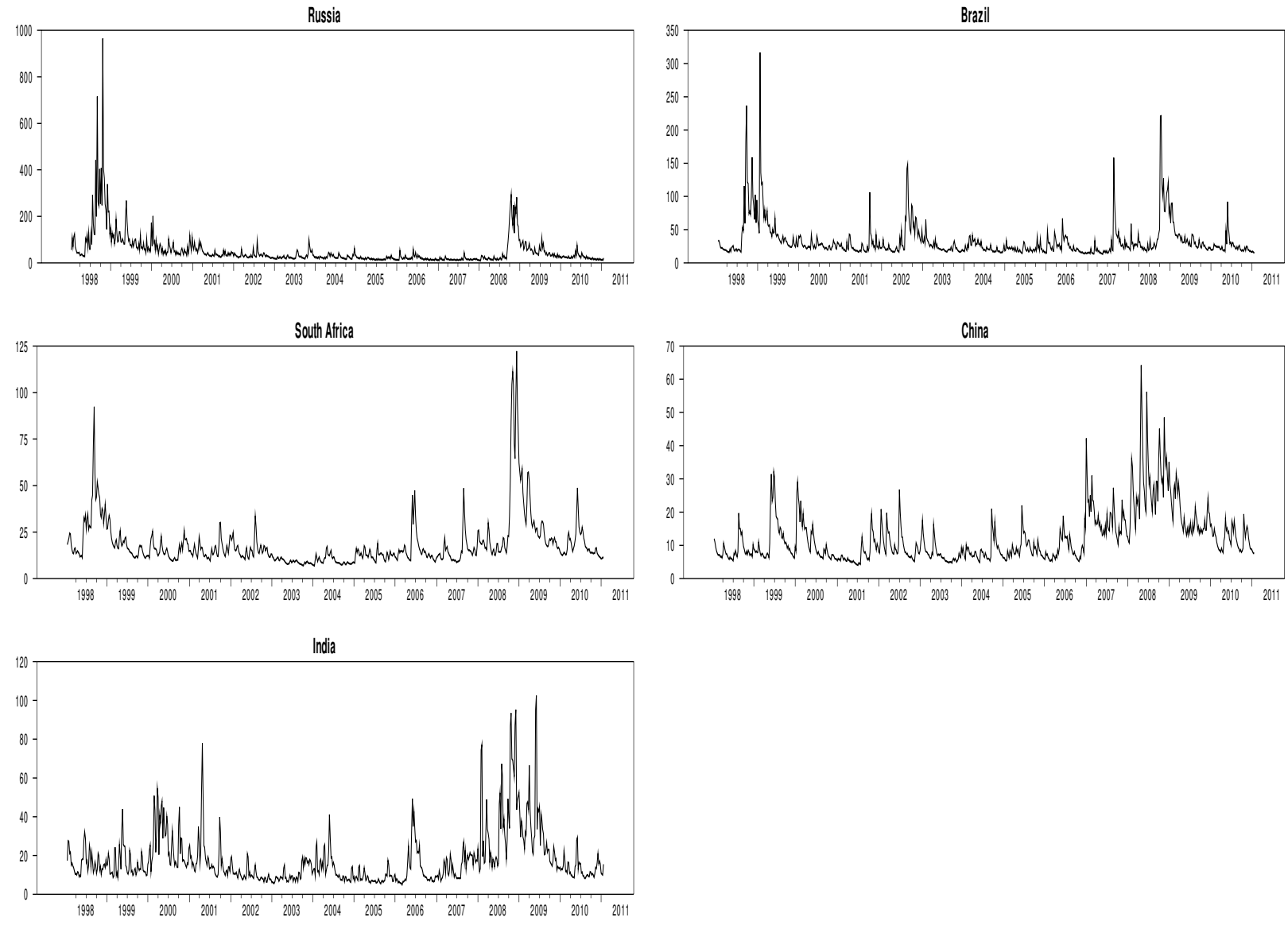

In the next step, the computed BRICS' equity market conditional volatilities are used to estimate the volatility spillover index and its dynamics by making use of the forecast error variance decomposition in the context of the generalised VAR framework. The volatility spillover, as well as the spillover index, is computed by making use of a 10-week forecast horizon in obtaining the forecast error variance. Nonetheless, to control for the influence of the global financial shocks on BRICS countries, the estimated VAR model includes the US conditional volatility as an 
exogenous variable. It is important to note that conditional volatility of the US equity market is modelled with the use of the EGARCH $(1,1)$, which provides the highest loglikelihood value.

The paper provides the full sample analysis of volatility spillover, as well as the rolling-sample analysis, to account for the possible changes that occur in the transmission of volatility shocks between BRICS countries during the periods covered by the paper. With regard to the full sample analysis, the $i j$ th cell in Table 2 presents the computed volatility spillover values, which represent the estimated contribution to the forecast error variance of country $i$ coming from shocks to country $j$. For example, one can read from Table 2 that shocks to Russia's volatility are responsible for $20 \%$ of the error variance in forecasting the 10-week-ahead South African volatility but only $0.3 \%$ of the error variance in forecasting Chinese volatility. The amounts indicate that volatility spillovers from Russia to South Africa are larger than from Russia to China. Moreover, the results reported in Table 2 show that volatility spillovers from South Africa to other BRICS countries are much lower $(14 \%)$ than total volatility spillovers from other BRICS countries to South Africa (31\%). This result shows that South Africa is more of a receiver of volatiltiy spillovers from other BRICS countries than a transmitter of volatility to other BRICS economies. This asymmetric transmission of volatility spillover between BRICS countries does not augur well for the principle of risk sharing, which is an important condition for beneficial financial integration in the face of full capital market liberalisation.

Table 2. Volatility spillovers between BRICS countries

\begin{tabular}{|l|l|l|l|l|l|l|}
\hline & Russia & SA & India & Brazil & China & $\begin{array}{l}\text { From } \\
\text { Others }\end{array}$ \\
\hline Russia & 88.8 & 8.3 & 0.3 & 1.9 & 0.7 & 11 \\
\hline South Africa & 20 & 68.7 & 5.8 & 4.5 & 1 & 31 \\
\hline India & 1.1 & 1.9 & 93.7 & 0.6 & 2.7 & 6 \\
\hline Brazil & 16.6 & 4 & 1.3 & 77.5 & 0.6 & 22 \\
\hline China & 0.3 & 0.1 & 1.1 & 0.4 & 98.1 & 2 \\
\hline Contribution to others & 38 & 14 & 8 & 7 & 5 & 73 \\
\hline Contribution including own & 127 & 83 & 102 & 85 & 103 & $14.60 \%$ \\
\hline
\end{tabular}

Another important result that emerges from Table 2 is that the spillover index, which is the summary of all the cross-country spillover, is $14.60 \%$. This estimation of the spillover index suggests that a great deal of volatility within BRICS countries $(85.40 \%)$ is due to shocks from other sources than BRICS cross-country spillover. This reality is confirmed in Figure 3, which depicts the cyclical movement in volatility spillover between BRICS countries. Figure 3 is obtained by estimating the model using 120 -week rolling samples of spillover indices. The cyclical spillover plot in Figure 2 shows that periods of high volatility spillover between BRICS countries corresponds to global financial and economic events such as:

- The Brazilian currency crisis in 1999, which further spread to other Latin American coutries as well as most emerging markets; 
- The burst of dot-com bubble or information technology bubble with NASDAQ composite index losing more than 10\% from its peak and emerging equity market being considerably affected by the collapse of the NASDAQ;

- The Latin American crisis of 2001 and 2002 - mostly triggered by currency crisis in Argentina and Brazil;

- The US terrorist attack of September 2001, which was another important event that affected global financial markets;

- The strong signal by the US Federal Reserve Bank to hike in the Fed Funds rates in May 2006, which triggered massive capital flows from emerging markets; and

- The subprime mortgage crisis, which triggered a global financial crisis.

Figure 2 cyclical movements in the spillover of BRICS

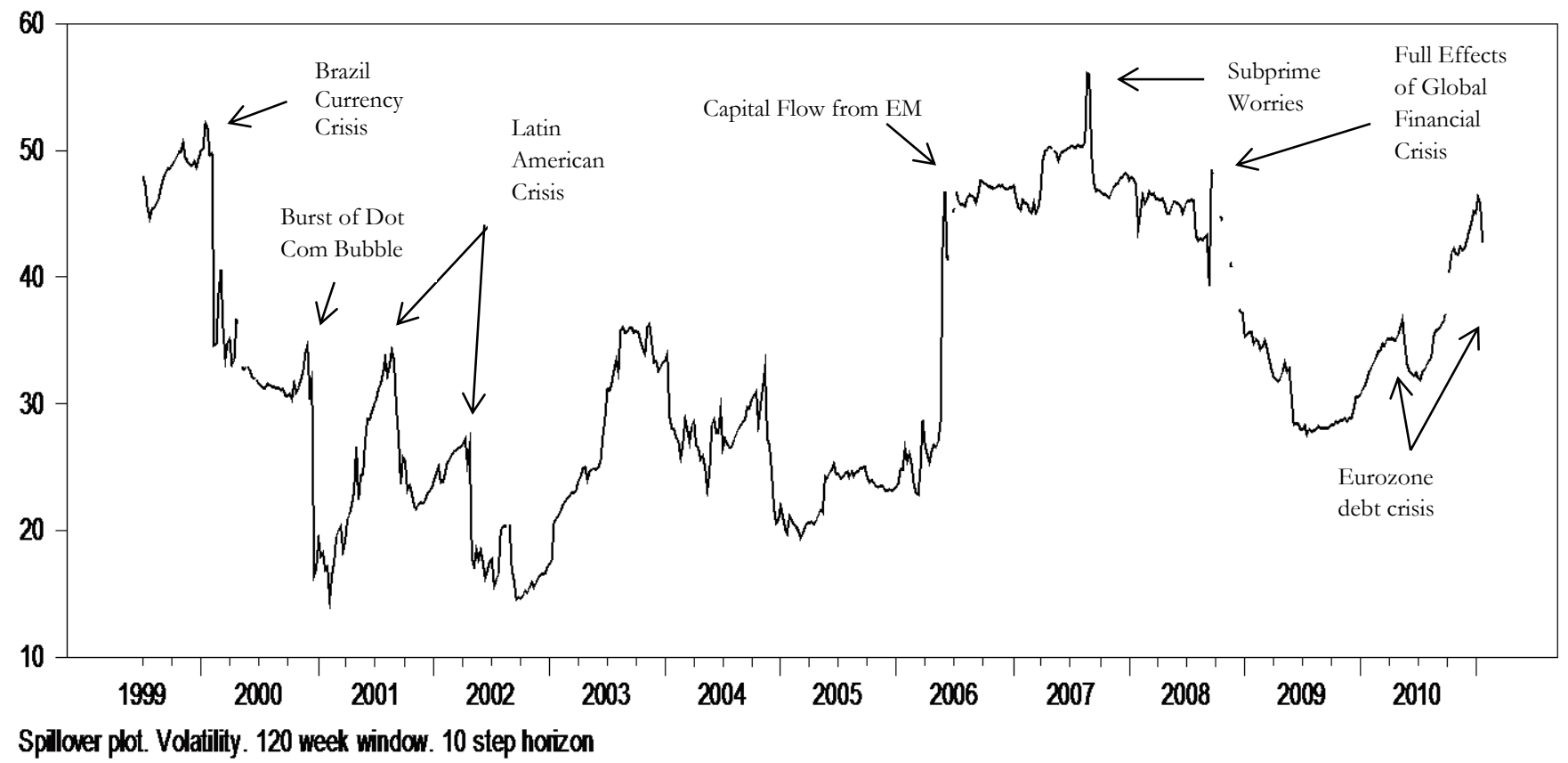

The rolling sample spillover index plot reveals clearly how emerging markets in general and BRICS countries in particular are more affected by global events than by local and regional events. This reality suggests that not only there is asymmetric transmission of shocks between BRICS countries but these countries are not insulated from global financial events that can affect their capital movements. Asymmetric transmission of volatility shock indicates that any initiative for full capital market liberalisation will create losers and winners within the BRICS countries. China, the less affected by volatility shocks of other BRICS countries, may become the safe haven drawing capital from other BRICS countries.

In order to test the robustness of our results, we estimated this time the volatility spillover and the spillover index by making use of the forecast error variance obtained from a 2-week-ahead forecast horizon. The results reported in Table 3 show that the pattern of cross volatility spillover did not change. The results show that South Africa is still highly influenced by other 
BRICS countries, with $38 \%$ of its equity volatility emanating from other BRICS countries and propagating a total of $16 \%$ of volatility shocks to other BRICS countries.

Table 3. Volatility spillovers between BRICS countries from a 2-week-ahead forecast horizon

\begin{tabular}{|l|l|l|l|l|l|l|}
\hline & Russia & SA & India & Brazil & China & $\begin{array}{l}\text { From } \\
\text { Others }\end{array}$ \\
\hline Russia & 86.2 & 10.1 & 1.1 & 1.9 & 0.8 & 14 \\
\hline South Africa & 23.1 & 62 & 4.1 & 8.7 & 2.2 & 38 \\
\hline India & 2 & 1.4 & 92.7 & 1.4 & 2.6 & 7 \\
\hline Brazil & 13.6 & 4.8 & 1.3 & 77.4 & 2.9 & 23 \\
\hline China & 1.1 & 0.1 & 0.2 & 0.4 & 98.2 & 2 \\
\hline Contribution to others & 40 & 16 & 7 & 12 & 8 & 84 \\
\hline Contribution including own & 127 & 78 & 99 & 90 & 107 & $14.60 \%$ \\
\hline
\end{tabular}

The spillover index remains low at $16.70 \%$, indicating the vulnerability of the BRICS countries to volatility shocks emanating outside of the grouping. These findings confirm the asymmetric propagation of shocks in the BRICS grouping with South Africa being a receiver rather than propagators of volatility shocks within the BRICS grouping. The vulnerability of South Africa to shocks from other BRICS countries indicates that caution must be exercised before South Africa approves any legislation that supports full capital market liberalisation, albeit between BRICS countries. Being the least influenced by volatility shocks from other BRICS countries, China may become the safe haven of the BRICS grouping benefiting from full capital market liberalisation by attracting portfolio investment, especially during periods of financial crisis. Just as Mendoza et al. (2009) indicate that the US benefited from globalisation by attracting risky asset mainly from small and vulnerable economies, China may become the net beneficiary of risky assets from other BRICS countries in case BRICS grouping opts from full capital market liberalisation.

\section{Conclusion}

This paper endeavoured to assess the extent of the cross transmission of volatility shocks or risk sharing between BRICS countries in order to be able to infer their readiness for full capital market liberalisation. Making use of the spillover index obtained from the forecast error variance, the paper finds that the cross transmission of volatility spillover is asymmetrically distributed between BRICS countries. The smaller countries in the grouping, such as South Africa, are more receivers than transmitters of volatility shocks within the grouping. Such an asymmetric transmission of shocks denotes the risk of massive capital outflow from small BRICS countries to more influential countries such as China, which seems insulated from volatility shocks from other BRICS countries. The paper suggests that it is too soon for BRICS countries to think about full capital market liberalisation at this time because of this asymmetric risk sharing. For future research, we suggest that other measures of risk sharing be used to assess the extent of the transmission of risks between BRICS countries. 


\section{References}

Baillie, R.T., Bollerslev, T., Mikkelsen, H.O. (1996). Fractionally integrated generalized autoregressive conditional heteroskedasticity. Journal of Econometrics 74: 3-30.

Bekaert, G.; Harvey, C.R. and Lunbla, C. (2005). Does financial liberalisation spur growth? Journal of financial economics, $77(1): 3-56$.

Diebold, F. X. \& Yilmaz, K. (2012). Better to give than to receive: Predictive directional measurement of volatility spillovers. International Journal of Forecasting, 28(1):57-66.

Diebold, F.X. and Yilmaz, K. (2009). Measuring Financial Asset Return and Volatility Spillovers, with Application to Global Equity Markets," Economic Journal, 119(534): 158-171.

International Monetary Fund (2012). World Economic Outlook. International Monetary Fund, Washington, DC.

Kalemli-Ozcan, S., Manganelli, S., Papaioannou, E., Peydró, J.-L. (2009). Financial integration and risk sharing: the role of monetary union, in: Mackowiak, B., Mongelli, F. P., Noblet, G., Smets, F. (Ed.), the euro at ten: lessons and challenges, 116-155, European Central Bank.

Koop, G. and Pesaran, M. H. and Potter, S. M. (1996). Impulse response analysis in nonlinear multivariate models," Journal of Econometrics, 74(1): 119-147.

Kose, M. A; Prasad, E. S. and Taylor, A. D. (2011). Thresholds in the process of international financial integration. Journal of International Money and Finance, 30(1): 147-179.

Kose, M.A; Prasad, E. and Terrones, M.E. (2009). How doe financial globalisation affect risk sharing? Pattern and Channels. Journal of Development Economics, 89(2): 258-270.

Lamoureux, C. G. and Lastrapes, W. D. (1990). Persistence in variance, structural change and the GARCH model. Journal of Business and Economic Statistics, 8(2): 225-234.

Mendoza, E.G.; Quandrini, V. and Rios-Rull, J.V. (2009). Fincial integration, financial development and global imbalances. Journal of political economy, 117(3): 371-416.

Pesaran, H. H. and Shin, Y. (,1998). Generalized impulse response analysis in linear multivariate models. Economics Letters, 58(1):17-29.

Stiglitz,J.E. (2002). Globalization and its discontents. Economic notes 32(1): 123-142.

World Bank (2012). World development indicators 2012, Washington, DC. https://openknowledge.worldbank.org/handle. Accessed 16 April 2014. 
Appendix

Figure A1 Autocorrelation function of absolute returns of BRICS equity markets returns
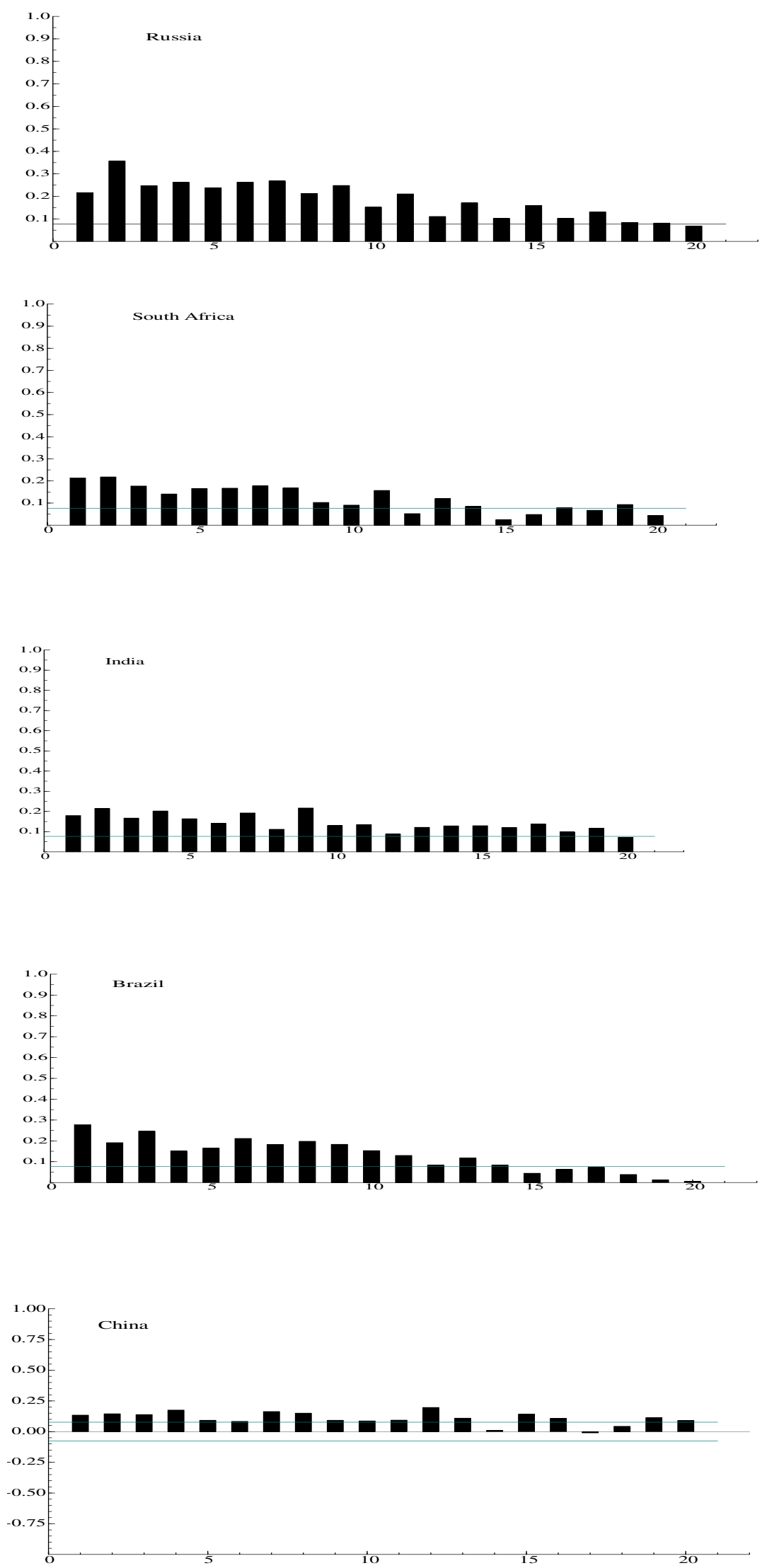
